\title{
Study on Improving Teaching Team Ability Sino-foreign Cooperative Education of Higher Vocational Colleges
}

\author{
Junliang Zheng \\ Shunde Polytechnic, Foshan, 528329, China
}

Keywords: Higher vocation colleges, Sino-foreign cooperation, Teaching team ability; TAFE.

\begin{abstract}
This paper takes Australian TAFE project as the object of study and designs teaching team ability index system for Sino-foreign cooperative education of higher vocational colleges on the basis of TT-CMM model. The influence degree of each ability index on comprehensive score of team is tested through modeling, and relevant development suggestions are proposed.
\end{abstract}

\section{Teaching team ability teaching team standards of Sino-foreign cooperative education of higher vocational colleges}

Jiang Lin and his team (2012) further studied teaching team ability evaluation on the basis of studying teachers' individual ability evaluation and improvement system based on CMM, proposed and constructed teaching team ability index system. We can see from their statement that, teaching team ability they studied is a comprehensive ability. Meanwhile, they constructed team ability maturity model TT-CMM and divided teaching team ability into five levels according to the maturity degree. This paper takes TAFE as the object of study, refers to TT-CMM model and combines actual conditions of higher vocational colleges which pay attention to skill training and requirements of Sino-foreign cooperative education to design TAFE teaching team ability index system. The influence degree of each ability index on comprehensive ability of the team is inspected by modeling.

Table 1. TAFE teaching team ability evaluation index of higher vocational colleges

\begin{tabular}{|c|c|c|}
\hline $\begin{array}{l}\text { First-level } \\
\text { index }\end{array}$ & $\begin{array}{l}\text { Second-level } \\
\text { index }\end{array}$ & Detailed index \\
\hline \multirow{2}{*}{ Team ability } & Team structure & $\begin{array}{l}\text { Quantity scale, age structure, educational background structure, } \\
\text { specialty structure, job title structure }\end{array}$ \\
\hline & Team experience & Qualification certificate, work experience, teaching experience \\
\hline \multirow{2}{*}{$\begin{array}{l}\text { Team } \\
\text { management }\end{array}$} & $\begin{array}{l}\text { Management } \\
\text { system and } \\
\text { culture }\end{array}$ & $\begin{array}{l}\text { Management level of leader, common goal, system establishment, } \\
\text { team culture }\end{array}$ \\
\hline & Team operation & $\begin{array}{l}\text { Professional ability complementation, labor division and } \\
\text { cooperation, internal communication, operating efficiency }\end{array}$ \\
\hline \multirow[b]{2}{*}{$\begin{array}{l}\text { Team } \\
\text { teaching }\end{array}$} & $\begin{array}{l}\text { Conventional } \\
\text { teaching }\end{array}$ & $\begin{array}{l}\text { Knowledge and resource sharing, teaching evaluation, teaching } \\
\text { discussion, teaching ability training }\end{array}$ \\
\hline & $\begin{array}{l}\text { TAFE teaching } \\
\text { requirement }\end{array}$ & $\begin{array}{l}\text { Teaching environment coordination ability, teaching design ability, } \\
\text { classroom teaching and learning ability promotion, training } \\
\text { consultation service ability, language and mathematic presentation } \\
\text { skills, other general abilities }\end{array}$ \\
\hline $\begin{array}{c}\text { Team } \\
\text { innovation }\end{array}$ & Team innovation & Innovation ability \\
\hline $\begin{array}{c}\text { Team } \\
\text { performance }\end{array}$ & $\begin{array}{c}\text { Team } \\
\text { performance }\end{array}$ & $\begin{array}{l}\text { Teaching objective realization, student assessment, capacity for } \\
\text { scientific research, teaching enthusiasm, teaching research result }\end{array}$ \\
\hline
\end{tabular}


Regression analysis of teaching team ability of Sino-foreign cooperative education for higher vocational colleges - case study of Guangdong TAFE project

Guangdong Province carried out Sino-foreign cooperative education of higher vocation colleges early and has accumulated rich experience in this aspect. Based on document research and interview, we designed a questionnaire according to TAFE teaching team ability evaluation indexes of higher vocational colleges and surveyed higher vocational colleges in Guangdong Province which implemented TAFE project in the form of survey questionnaire and group discussion. 80 questionnaires were distributed, and 74 questionnaires were recovered. All the 74 questionnaires are effective.

We established regression model for TAFE teaching team ability indexes of higher vocational colleges, took comprehensive ability self-evaluation of team (v57) as the dependent variable and used stata statistical software to test relevance of other ability indexes and team ability.

\section{Regression analysis of comprehensive ability score and team structure.}

We adopted backward step-by-step search method for stepwise regression to eliminate the influence of multicollinearity. The analysis result shows that fit goodness of the model is good. Quantity scale v7, age structure v9, educational background structure v10, specialty structure v11, satisfaction of team members for joy title structure v14, satisfaction of team members for educational background structure v15 and scientific attainments of leader v20 have significant influence in team ability improvement. The scientific attainments of quantity scale is negative, which to some extent explains the more quantity of teaching staffs is not always the better, and there is a rational quantity scale. Meanwhile, the coefficient of scientific attainments of leader v20 is negative, and v20 is closely related to the authority of teaching team. The educational circle in China has the custom of upholding academic authority, so too high scientific attainments will hinder active degree of other team members, including proposal of opinions and suggestions and query of leader's opinion. This does not contribute to improving team ability.

To eliminate the influence of multicollinearity on the model, backward step-by-step search method is adopted for regression analysis.

Regression analysis of comprehensive ability score and team experience.

It is found from regression analysis of team experience indexes that, the influence of team experience v18 on comprehensive ability is not significant; the significance of qualification certificate v17 and team teaching experience v13 is high.

Regression analysis of comprehensive ability score, management system and culture.

After the regression, the fitting degree of the model is excellent. The influence of management level of leader v21 and system establishment v27 is not significant, while the influence of common goal v23, incentive mechanism v29 and team culture v30 is significant.

Regression analysis of comprehensive ability score and team operation.

The regression analysis shows that labor division and cooperation v25 and team trust v33 in team operation have significant influence on comprehensive ability.

Regression analysis of team ability and conventional teaching requirements.

The regression analysis shows that teaching evaluation diversity v34 and teaching discussion v35 have significant influence on comprehensive ability.

Regression analysis of team ability and TAFE teaching requirements.

The results show that not all ability requirements are significant. Teaching design ability v38, classroom teaching and learning ability promotion v39 and other general abilities v42 have significant influence on comprehensive ability.

Regression analysis of comprehensive ability and team innovation ability.

The relation result of comprehensive ability and team innovation ability is not significant. It is necessary to notice that the square of adjusted $\mathrm{R}$ is about 0.02. Explanation degree of regression model is very poor. This indicates that their relation is not simple linear relation. Thus, it is necessary to further study their relevance. 


\section{Comprehensive ability and team performance.}

About the relevance of comprehensive ability and team performance, teaching objective achievement v47, teaching enthusiasm v50, and teaching and research achievements v51 pass significance testing, while the influence of student evaluation v48 and capacity for scientific research v49 on comprehensive ability is not significant

\section{Suggestions on improving teaching team ability development of Sino-foreign cooperative education for higher vocational colleges}

a) Optimize age structure. A teaching team in which "both ends are small and the middle is large" should be built. In other words, senior teachers who engage in college teaching for a long term are dominated, and middle-aged teachers serve as the subjects. Young teachers should be allocated rationally to form a teaching team which are composed of old, middle-aged and young teachers and can adapt teaching and scientific research. It is necessary to confirm specialty development goal, task and requirement according to talent training scheme and overall plan teaching team building.

b) Establish common goal of the team. Common goal is a basic condition of teaching team constitution, and also the key of teaching team maintenance. Based on the common goal, team members can give full play to their advantages and ability. The establishment of common goal needs to follow certain principles. The common goal should serve for the whole development objective of cooperative education. The common goal of teaching team development is confirmed according to the requirements of higher vocational education for training high-tech talents by "combining learning with working and cooperating between colleges and enterprises. During the establishment of common goal, individual goal achievement should be considered. In other words, the realization of common goal needs to contribute to individual goal realization and individual ability development. Inconsistency exists between common goal and individual goals of members, which may hinder the realization of team goal. On the contrary, if the common goal is approved by the members, this will contribute to exerting individual enthusiasm.

c) Create favorable team culture. An excellent teaching team with favorable team culture should own the following features: common and clear goal; harmonious team atmosphere; atmosphere and cooperation mechanism; team spirit. To create favorable team culture, firstly, an appropriate teaching team leader should be chosen. In the process of forming team culture, the function of a leader is very obvious. The leader should not just have high uniform specialty ability and leadership, but also should have certain individual prestige and personality charm. Team members are the construction subjects of team culture. Hence, basic stability of backbone members should be guaranteed, and there should be rational team flow. On the one hand, this is beneficial to cultural deposits; on the other hand, new factors can blend. It is required to rationally set team development vision and closely connect with individual vision, and ensure common development of team and individuals. Besides, it is required to actively advocate teacher cooperation culture, enhance cooperation awareness and carry out diversified cooperation by taking scientific research as the platform.

d) Teaching evaluation diversification. Existing teaching evaluation includes external and internal evaluation. External evaluation refers to overall teaching evaluation organized by competent department of education. Internal evaluation refers to teaching evaluation of teaching team or individuals organized by college departments. External evaluation has integrality and non-lasting property, so we pay more attention to internal teaching evaluation mode. It is required to continuously study and improve team teaching evaluation method, carry out dynamic evaluation and differential evaluation according to teachers' individuality and the changes of teaching situation. Meanwhile, the evaluation should be open and transparent. Evaluation content, evaluation mode and evaluation subject should be diversified. Evaluation content diversity refers to evaluation of teaching achievement, teaching process and teaching design. Evaluation mode diversity refers to organization of open class and speaking lesson, except listening in classroom. Evaluation subject diversify refers to the inclusion of team members, teaching team leader, college supervisor and teaching self-evaluation, except students. Development evaluation of teachers should be formed. Development 
evaluation aims to judge teaching on the basis of deeply knowing teachers' teaching situation, and help teachers improve teaching ability through various effective approaches. To provide good safeguard mechanism for sustainable development of teaching team, the system which combines college evaluation, student evaluation and team self-evaluations should be established.

e) Improve team incentive mechanism. In order to fully mobilize working enthusiasm, initiative and creativity of team members, necessary incentive mechanism in terms of material, spirit and vocational development should be established, including allowance and money award for excellent teachers. Besides, a typical mode should be established to let teaching team members be full of the sense of honor. Social feeling motivation meets human demand of better level. Social feelings such as honor, friendship, trust and praise can mobilize members' enthusiasm. More importantly, the incentive mechanism which promotes individual development of team members should be established. Moreover, it is required to create conditions for teachers' external training and job title appraisal, organically combine specialty building with teachers' individual development, guide teachers to make efforts for team goal achievement and consider construction of team-oriented performance evaluation and incentive system. For a long time, colleges have implemented individual-oriented performance evaluation and incentive system, and only pay attention to the first principal for various activities and ignore other participants. Such evaluation mode obviously goes against teacher cooperation, and even plays the opposite role. After the teaching team forms, teachers' teaching work should comply with management requirements of the whole teaching team, and teachers' individual performance evaluation should be changed to team performance evaluation. It is required to achieve the transformation to "colleges assessing the team and the team assessing individuals" and really regard teaching team as a whole.

f) Improve "double-quality teacher" structure and achieve "combination of part time and full time”. Colleges introduce full-time teachers with enterprise experience, train existing full-time teachers and employ part-time teachers from enterprises. The three methods are the basic approaches to create the teaching tram with "double-quality teacher" structure. The three methods cannot be separated from enterprise participation and support. College-enterprise cooperation is a complex and systematical project, so it must involve the college, government, industry and enterprise so as to form long-term safeguard mechanism. The government should formulate relevant policies, schemes sand rules, establish laws and regulations on enterprises' participation in vocational education, specify responsibilities and obligations of enterprises in talent training system and promote college-enterprise cooperation. Enterprises should establish correct college-enterprise cooperation awareness and cognize the important significance of college-enterprise cooperation on corporate image improvement and talent reserve. In addition, enterprises should actively choose engineering technicians and skilled persons to take a part-time job in higher vocational colleges, feed back new technology and new process in time, participate in teaching reform, create conditions for training “double-quality” teachers and offer service and help for improving students' operation ability, colleges should attach importance to training and improvement of teachers' practical ability, encourage teachers to train in enterprises and improve practical teaching ability. Meanwhile, colleges should actively employ technical backbones in the industry and enterprise to take a part-time job in colleges and build part-time teaching staffs of "college-enterprise interaction and dynamic combination". Additionally, colleges should establish flexible employment and compensation plan so as to improve the treatment of part-time teachers.

Perfect management system and improve operating efficiency. Whether a teaching team can operate in an efficient and orderly way, the key is whether there is a set of policies and systems beneficial to teaching team development. Colleges play an irreplaceable role in policy and system environment creation. In Chinese colleges, the quantity of high-level teaching teams is small. It is hard for teachers to achieve real team cooperation and to give full play to the function of teaching team. This is mainly because there is short of system environment beneficial to team formation and development. Improvement of system environment of colleges is an important precondition of giving play to the function of teaching team. It is required to reform and improve power disposition mode of colleges, establish the principle of proper separation of administrative power and academic power 
and make political affairs and academic affairs clear. It is required to confirm the position of academic power institutionally, respect the existence of academic power, further decentralize and expand management autonomy of the team. For the method of teaching work completion, teaching content and schedule, power of mobile personnel, internal assessment right and the right of eliminating unqualified personnel, the team should make decisions independently. Only when the teach has more autonomous rights can responsibility sense and work initiative of the team be enhanced, internal management and operating mechanism of the team are the key to successful teaching team.

\section{Acknowledgments}

This paper is general topic of education science planning project in Foshan City, No.: FSZZgy2013034.

\section{References}

[1] Jiang Lin, Hu Zhigang, Yang Liu, Teaching team ability evaluation and continuous improvement method oriented to excellent project talent training, Research in Higher Education of Engineering, 2012,(6):31-37.

[2] Liang Songhe, Wang Yulian, Exploration of theoretical foundation and value of college teaching team building, China Adult Education, 2013,(6).

[3] Ji Shuhong, Gao Chaqing, “Double-quality” teaching team of higher vocational colleges: connotation and construction elements, Vocational and Technical Education, 2012,33(674):49-53. 